\title{
IV. DIE TROIS-ÉVÊCHÉS UND DAS REICH
}

In den bisherigen Abschnitten, die sich vornehmlich mit der französischen Politik nach 1552 befaßt haben, blieb ein Akteur weitgehend unberücksichtigt: das Reich, zu dessen Verband die Gebiete zuvor gehört hatten und nominell immer noch gehörten. Der folgende Abschnitt soll daher kurz anreißen, wie das Verhältnis der Trois-Évêchés zum Reich während der geschilderten Ereignisse war, welche Rolle die Frage der Restitution der von Frankreich besetzten Gebiete auf den Reichstagen und in der Reichsdiplomatie spielte und wie stark die Bindungen zwischen dem Reich und Metz, Toul und Verdun im Bereich von Recht und Gerichtsbarkeit sowie insbesondere zum Reichskammergericht waren.

\section{Die Situation vor 1552}

Bezeichnend für das Verhältnis der Trois-Évêchés zum Reich in den Jahren vor 1552 ist ein Schreiben der Bischöfe von Metz, Toul und Verdun an den Reichstag in Regensburg aus dem Jahr $1532^{1}$. Dieses Dokument, das 1890 von Winkelmann ediert und kommentiert wurde, steht im Zusammenhang mit einem sehr ähnlichen Gesuch des lothringischen Herzogs ${ }^{2}$.

In dem Schreiben schildern die Bischöfe die Lage ihrer drei bistumb oder stieff [...] in den landen Lothringen, Barre unnd andern neben frembden herschaften gelegen, welliche zumal des beczirck des heiligen Romischen reichs vfgeschlossen am kunigreich von franckreich anstossig. Seit Menschengedenken seien diese Gebiete frei gewesen und allein von den Bischöfen regiert worden. Nur wegen zahlreicher Kriege hätten sich diese vor rund 600 Jahren entschlossen, beim Reich Schutz zu suchen. Ihre Gebiete seien auch dann frembde land geblieben, und nit im begriff der teutschen nation noch in irem gezwang gewesen. Metz, Toul und Verdun hätten, wie dann weiter aus zahl-

\footnotetext{
' Dies waren Jean de Lorraine, Bischof von Metz und Verdun und Hector d'Ailly de Rochefort, Bischof von Toul.

${ }^{2}$ Otto WINKELMANN, Beiträge zur Geschichte der staatsrechtlichen Beziehungen Lothringens zum Reich im 16. Jahrhundert, in: Jahrbuch der Gesellschaft für lothringische Geschichte und Altertumskunde 2 (1890) S. 185-213. Dort ist auch das Schreiben des Herzogs, auf das an dieser Stelle nicht näher eingegangen werden kann, ediert und kommentiert.
} 
reichen Quellen und Rechtstexten belegt wurde, nur den Status eines Freilehens gehabt und seien nie zu Reichssteuern herangezogen worden. Die Randlage sei aber auch der Grund, warum das Reich diese Gebiete gar nicht ausreichend beschützen könne, und auch deshalb sei es nicht gerecht, die Trois-Évêchés zur Zahlung von Reichssteuern zu veranlagen. Dennoch, betonten die Bischöfe, seien sie willig vnnd urburtig [...], des romischen heiligen reichs getrewe lehens fursten und hern zu sin vnnd bliben ${ }^{3}$.

Das Schreiben macht deutlich, wie stark bereits vor den Ereignissen von 1552 der Unterschied zur teutschen nation wahrgenommen wurde. Dem Kaiser gegenüber versicherten die Bischöfe gleichzeitig, abgesehen von der Zahlungsverpflichtung, ihre Treue. In ganz ähnlicher Weise und Terminologie ging man in Metz und Verdun vor 1552 allerdings auch mit dem französischen König um ${ }^{4}$. Ebenso wie die Bischöfe betrieb auch der Rat der Stadt Metz in verschiedenen Gesandtschaften und Bittbriefen ständig eine Verringerung der Steuerlast gegenüber dem Reich, mit fast identischen Argumenten: Genannt wurden die Randlage, die altangestammten Rechte und Privilegien sowie der Status von Metz als einem der vier Hauptorte des Reiches ${ }^{5}$.

Erfolg hatten die Bemühungen jedoch nicht: Im Gegensatz zum Herzogtum Lothringen, dessen ähnlichem Anliegen 1542 mit dem Vertrag von Nürnberg stattgegeben wurde, gestand der Kaiser den Städten und Hochstiften Metz, Toul und Verdun ihre Steuerfreiheit nicht zu und vertagte deren Anliegen statt dessen auf den nächsten Reichstag in Speyer. Zwar wurden bis dahin die bereits begonnenen Ermittlungen des Fiskalprokurators, der ein Gerichtsverfahren gegen die drei Städte und Stifte begonnen hatte, ausgesetzt, doch die Zahlungsverpflichtung zur Türkenhilfe blieb, schon als ein gemain cristenlich guet werkh, bestehen ${ }^{6}$. Dies trug, so vermutet Charles Aimond, zusammen mit den Aufenthalten des Kaisers und seiner Armee in der Region in den Jahren 1534 und 1535 nicht unerheblich dazu bei, beispielsweise die Beziehungen zwischen Verdun und dem Reich merklich abzukuhlen? ${ }^{7}$ Wohl auch aus diesem Grund bemühte man sich in den Trois-Évêchés im Konflikt zwischen dem Kaiser und dem französischen König um Neutralität: So erhielt Bischof Jean de Lorraine für Metz und Verdun 1542 Neutralitätsbriefe von beiden Seiten ${ }^{8}$.

\footnotetext{
${ }^{3}$ Nach dem bei Winkelmann abgedruckten Text: WINKELMANN, Beiträge, S. 207-212.

${ }^{4} \mathrm{Vgl}$. hierzu den ersten Band der Arbeit von ZELLER, Réunion, sowie AIMOND, Rélations.

${ }^{5}$ Vgl. ZELLeR, Réunion, Bd. 1, S. 207-235, zum Status der Hauptstadt S. 208f.

${ }^{6}$ Die Antwort des Kaisers ist ebenfalls bei WINKELMANN, Beiträge, S. $212 \mathrm{f}$. gedruckt.

${ }^{7}$ AIMOND, Rélations, S. 362f.

${ }^{8}$ Ibid. S. $366 f$.
} 


\section{Die Frage der Trois-Évêchés auf den Reichstagen und in der Diplomatie nach 1552}

Nach der Besetzung von Metz durch französische Truppen setzten vor allem die durch Bischof Robert de Lenoncourt entmachteten Vertreter des städtischen Patriziats in Metz auf Unterstïtzung aus dem Reich, von dessen Eingreifen sie sich eine Wiederherstellung ihrer alten Position in der Stadt erhofften. Mehrfach forderten sie die Befreiung ihrer Stadt von der "Tyrannei« des Bischofs und des französischen Königs und wurden dabei stets auf den nächsten Reichstag vertröstet'. Die konfessionellen Auseinandersetzungen im Reich ließen den Kurfürsten und Vertretern des rheinischen Kreises kaum Gelegenheit, den besetzten Gebieten in Lothringen noch große Aufmerksamkeit zu schenken ${ }^{10}$.

Der Kaiser war grundsätzlich aber weiterhin bestrebt, Metz, Toul und Verdun wieder unter seine Kontrolle zu bringen. Das Anliegen der Metzer Patrizier hatte vor dem angekündigten Reichstag zu Augsburg insofern Erfolg, als der frankreichtreue Bischof Robert de Lenoncourt nicht mehr zum Reichstag geladen wurde und sich zudem vedpflichtig gemacht hatte ${ }^{11}$. Der französische König Heinrich II. aber war, nicht zuletzt durch die große Aufmerksamkeit, die die erfolgreiche Verteidigung der Stadt in ganz Europa auf sich gezogen hatte, kaum noch bereit, ma ville de Metz ${ }^{12}$ wieder an den Kaiser herauszugeben. Die von Vertretern des Papstes und des englischen Königs moderierten Verhandlungen zwischen Heinrich II. und Kaiser Karl V. im Jahr 1553 scheiterten deshalb an der Unnachgiebigkeit beider Herrscher in dieser Frage ${ }^{13}$.

Die Verhandlungen im Jahr 1555 in Marck warfen erneut die Frage der Trois-Évêchés auf, und die Instruktion der französischen Verhandlungsführer macht deutlich, daß man in Frankreich weiter mit einer unnachgiebigen Position des Kaisers rechnete. Hier hieß es, einer der wichtigsten Punkte, den die Kaiserlichen leidenschaftlich verfolgten und der ihnen sehr wichtig sei, sei es, die Städte Metz, Toul und Verdun in ihren Zustand als Reichsstädte zurückzuversetzen $^{14}$. Eine weitere Instruktion des französischen Kanzlers Olivier an

\footnotetext{
${ }^{9}$ ZeLLER, Réunion, Bd. 2, S. 22.

${ }^{10}$ Ibid.

${ }^{11}$ Vgl. die entsprechende Erwähnung im Reichstagsprotokoll von Hornung: Heinrich LUTZ, Alfred KOHLER (Hg.), Das Reichstagsprotokoll des kaiserlichen Kommissars Felix Hornung vom Augsburger Reichstag 1555, Wien 1971 (Österreichische Akademie der Wissenschaften Philosophisch-historische Klasse. Denkschriften, 103), S. 59.

${ }^{12}$ Heinrich II. in einem Brief an Marillac, vgl. ZELLER, Réunion, Bd. 2, S. 24.

${ }^{13}$ Ibid. S. 24-26.

${ }^{14}$ Reste à présent ung des principaulx poinctz, qui est des villes de Metz, Toul et Verdun, que les Impériaulx poursuivront vivement, comme chose qui leur importe de beaucoup, estre
} 
den Verhandlungsführer Montmorency riet dazu, sich in der Sache der drei lothringischen Städte bedeckt zu halten. Tatsächlich aber wurde nicht viel über diese Frage gesprochen, sie wurde überdeckt von der Auseinandersetzung um andere Besitzungen ${ }^{15}$.

Währenddessen war in Augsburg der Reichstag zusammengetreten. Über die Ereignisse berichtet ein Reichstagsprotokoll aus der Hand des kaiserlichen Rates und früheren Trierer Kanzlers Felix Hornung ${ }^{16}$. Hornung notierte, da $\beta$ der Bischof von Metz um Ausgleich mit dem Reich bestrebt sei, und dem Reichstag brieflich angeboten habe, sich für sein Verhalten zu rechtfertigen ${ }^{17}$. Der adel und alte geschlecht der stat Metz trugen vor der Versammlung auch im Namen von Toul und Verdun ihr Anliegen um Unterstützung und Wiedereinsetzung in die alten Rechte vor ${ }^{18}$. Allerdings war der Reichstag in dieser Frage durchaus uneins: Während die geistlichen Fürsten eine entschiedenere Politik gegenüber dem französischen König forderten, waren die Vertreter des sächsischen Kurfürsten der Meinung, die Diskussion um Metz, Toul und Verdun dürfe die laufenden Friedensverhandlungen nicht gefährden und keinen Vorwand für neue Steuerforderungen des Kaisers zur Finanzierung eines eventuellen Kriegszuges nach Lothringen darstellen. Man bat den Kaiser schließlich nur, die Frage in den Verhandlungen von Marck anzusprechen ${ }^{19}$.

Heinrich II. bat gleichzeitig den Reichstag, seine Gesandten zu empfangen. Dies war erneut Anlaß für Diskussionen um die Frage der Trois-Évêchés. Weiterhin blieben die Fronten klar: Die geistlichen Stände und König Ferdinand bestanden darauf, die Zulassung der Gesandten des französischen Königs an die Bedingung der Herausgabe von Metz, Toul und Verdun zu knüpfen, während die weltlichen Fürsten die Meinung vertraten, man könne dem französischen König diese Bitte nach altangestammtem Recht nicht abschlagen. Schließlich beschloß man, der Bitte Heinrichs weder stattzugeben noch sie abzuschlagen und statt dessen in einem hinhaltenden Antwortbrief in vorsichtigen Worten an die Rückgabe der drei Städte, aber auch anderer Reichsgebiete, zu erinnern ${ }^{20}$.

remises en leur premier estat comme villes impérialles. Übertragung der Autorin, Zitat ibid. S. 28.

${ }^{15}$ Ibid. S. 29-31.

${ }^{16}$ Bibliothek des Priesterseminars in Trier, Handschrift 50, hg. v. LUTZ, KOHLER, Reichstagsprotokoll.

${ }^{17}$ LUTZ, KOHLER (Hg.), Reichstagsprotokoll, S. 59f.

${ }^{18}$ Das "Klagschreiben« ist wiedergegeben bei Franz Bernhard von BUCHOLTZ, Geschichte der Regierung Ferdinands I., Bd. 9, Wien 1836, S. $557 f$.

${ }^{19}$ ZELLER, Réunion, Bd. 2, S. 32.

${ }^{20}$ LUTZ, KOHLER (Hg.), Reichtagsprotokoll, S. 140-142. Die Antwort des versammelten Reichstages an den König Heinrich II. ist gedruckt bei ZELLER, Réunion, Bd. 2, Anhang, S. 321-323. 
Die Frage der Trois-Évêchés blieb auch weiterhin in der Schwebe: In den Verhandlungen zum Waffenstillstand von Vaucelles 1556 wurde sie gar nicht erst angesprochen. So bestätigte dieser im Hinblick auf Metz, Toul und Verdun den Status quo ${ }^{21}$. Verfolgt wurde die Frage der Restitution der TroisÉvêchés zu diesem Zeitpunkt weniger von kaiserlicher Seite als von einigen Reichsfürsten, wie August von Sachsen und vor allem Christoph von Wuirttemberg, der sich schon zuvor regelrecht zum Anwalt einer Restitution gemacht hatte ${ }^{22}$. In deren Verhandlungen mit Vertretern Heinrichs II. (die versuchten, auf diese Weise die habsburgische Thronfolge $\mathrm{zu}$ verhindern) brachten sie immer wieder die Frage nach Metz, Toul und Verdun auf ${ }^{23}$.

Der Waffenstillstand von Vaucelles blieb nicht von langer Dauer: Schon 1557 begannen die Auseinandersetzungen erneut. Einer der Auslöser war ausgerechnet ein angeblich vom kaiserlichen Gouverneur in Luxemburg geplanter Angriff zur Befreiung von Metz. Der Anlaß für diese Beschuldigung stand auf denkbar schwachen Füßen: Zwei Soldaten hatten sich im Streit gegenseitig der Spionage bezichtigt. Schon ein Jahr zuvor war in Metz ein ähnlicher »Komplott« aufgedeckt worden ${ }^{24}$. Gefährlich hätten diese angeblichen Verschwörungen jedoch nur werden können, wenn die kaiserlichen oder dann später die spanischen Truppen in der Stadt auf großen Rückhalt hätten zählen können. Eine militärische Aktion jedenfalls war von Seiten der Stadt nie gefordert worden, selbst von den entmachteten Mitgliedern der Patrizierschicht nicht.

Ein 1558 in Metz durch den französischen König ausgesprochenes Gottesdienstverbot für Protestanten rief eine andere Bevölkerungsgruppe der Stadt auf den Plan und weckte auch im Reich neue Solidaritäten. Die Metzer Protestanten wandten sich uber Straßburg an die evangelischen Reichsstände und baten diese um Unterstutzung. Beim Magistrat und wenig später auch beim königlichen Gouverneur Vielleville in Metz trafen daraufhin Briefe vom pfälzischen Kurfürsten, vom Herzog von Württemberg, vom Landgraf von Hessen, vom Markgraf von Baden, von den Pfalzgrafen Friedrich von Simmern und Wolfgang von Zweibrücken sowie vom Senat der Stadt Straßburg ein, die allesamt die Freiheit der Religionsausübung in Metz forderten ${ }^{25}$.

\footnotetext{
${ }^{21}$ Vgl. MiECK, Entstehung, S. 260, ZELLER, Réunion, Bd. 2, S. 33f.

${ }^{22}$ Vgl. seine zahlreichen Briefe zu diesem Thema: Briefwechsel des Herzogs Christoph von Wirtemberg, hg. v. V. ERNST, 4 Bde. Stuttgart 1899-1907, hier Bd. 2, S. 138f., 409, sowie Bd. 3, S. 2, 23-25 und Bd. 4, S. 82, 98f., 160, 599 u.ö.

${ }^{23} \mathrm{Vgl}$. zu den Verhandlungen Heinrichs II. allgemein RABE, Deutsche Geschichte, S. 458f. $\mathrm{Zu}$ den Verhandlungen Caius v. Virails mit August u. Christoph: vgl. ZELLER, Réunion, Bd. 2, S. 34f.

${ }^{24}$ Ibid. S. 35-38.

${ }^{25}$ Ibid. S. $43 f$.
} 
Auf dem Kurfürstentag zu Frankfurt 1558 wurde dann die Frage der Restitution von Metz, Toul und Verdun ausführlich beraten ${ }^{26}$. Eine Abordnung aus Metz trug ihr Anliegen vor und beklagte sich unter anderem darüber, daß die Vertreter der Stadt noch nicht einmal zu den Reichstagen geladen würden, so als ob Metz bereits nicht mehr zum Reich gehöre. Wieder blieben die Beratungen ohne Ergebnis: Das Anliegen wurde erneut vor den nächsten Reichstag verwiesen ${ }^{27}$. Wie ein Brief des spanischen Königs Philipps II. an Granvelle in Zusammenhang mit den Friedensverhandlungen in Cateau-Cambresis belegt ${ }^{28}$, stand auch dieser der Frage der Restitution keineswegs gleichgültig gegenüber ${ }^{29}$. Doch der französische König insistierte während der Verhandlungen geschickt auf einer Trennung zwischen den Interessen des spanischen Königs und denen des Kaisers. Er betonte, er verhandele in Cambrai lediglich mit dem spanischen König und könne nur mit dem Kaiser über die Trois-Évêchés sprechen $^{30}$.

1559 stand in Augsburg die Frage der Restitution dann erneut auf der Tagesordnung des Reichstages. Der französische König hatte sein seit vier Jahren angestrebtes Ziel erreicht, Vertreter zum Reichstag entsenden zu können. Er instruierte diese, auch weiterhin eine Hinhalte- und Verzögerungstaktik zu betreiben ${ }^{31}$. Die Gesandten aus Metz, zwei Mitglieder der Patrizierschicht und ein in Straßburg lebender Metzer Protestant ${ }^{32}$, trugen ihr Anliegen dem Reichstag am 30. März vor ${ }^{33}$. In langen Diskussionen setzte sich vor allem der Trierer Erzbischof, der als direkter Anrainer und Metropolitanbischof der Trois-Évêchés bereits auf dem Kurfürstentag von 1558 die Befürchtung geäuBert hatte, Frankreich plane eine Ausdehnung bis zum Rhein, für eine Restitution ein $^{34}$. Der Reichstag beschloß schließlich, die bedingungslose Rückgabe der Städte zu fordern, lehnte allerdings gleichzeitig jedes militärische Eingrei-

${ }^{26}$ Vgl. die Akten des Kurfürstentages in: Deutsche Reichstagsakten (im Folgenden RTA), Reichsversammlungen 1556-1662, Bd. 3: Der Kurfürstentag zu Frankfurt 1558 und der Reichstag zu Augsburg 1559, bearb. v. Josef LEEB, Teilband 1, Göttingen 1999, S. 377f., 381-385, 490 u.o.

${ }^{27}$ Ibid. Bd. 3,1, S. $508 \mathrm{f}$.

${ }^{28}$ Ibid. Bd. 3,1, Kurfürstenratsprotokoll, S. 578f.(Anm.).

${ }^{29}$ Vgl. RABE, Deutsche Geschichte, S. 466; sowie MIECK, Entstehung, S. 260. Auch ein Bericht der Vertreter des Herzogs Christoph von Württemberg auf dem Reichstag 1559 spricht für Spaniens Bemühungen um eine Restitution, vgl. dessen Briefwechsel, hg. v. ERNST, Bd. 4, S. 636.

${ }^{30}$ RTA, Reichsversammlungen, Bd. 3,1, Kurfürstenratsprotokoll, S. 579.

${ }^{31}$ Vgl. zum Verhalten der Gesandten: Ibid. Bd. 3,3, S. 1416-1427.

${ }^{32}$ Insbesondere die Biographie des Letzteren, der nicht als Interessenvertreter der Metzer Protestanten anzusehen ist, ist ausgesprochen interessant: vgl. ZELLER, Réunion, Bd. 2, S. 49-51.

${ }^{33}$ Text bei WinkelmanN, Beziehungen, S. 142-148. Zusammengefaßt auch in RTA, Reichsversammlungen, Bd. 3,3, S. 1411-1416.

${ }^{34}$ Vgl. ibid. Bd. 3,1, S. 382. 
fen ab. So war die Restitutionsforderung zur Wirkungslosigkeit verdammt ${ }^{35}$. Auch die Supplik der Metzer Protestanten, die auf dem Reichstag die Zulassung eines evangelischen Predigers gefordert hatten, wurde mit dem Argument, Metz gehöre derzeit nicht zum Reich, abschlägig beschieden ${ }^{36}$. Der im Vorjahr von den alten Geschlechtern von Metz auf dem Frankfurter Kurfürstentag erhobene Vorwurf, man habe Metz schon verloren gegeben, war also nicht ganz unberechtigt. In der Tat schien man sich im Reich trotz aller Absichtserklärungen für eine baldige Restitution darauf eingerichtet zu haben, daß Metz, Toul und Verdun nicht mehr Teil des Reiches waren ${ }^{37}$. Mit ihrem Verlust wurde sogar argumentiert: So hieß es, die Reform der Reichsmatrikel sei schon deshalb nötig, weil einige Gebiete, wie Metz, Toul und Verdun, mittlerweile nicht mehr zum Reich gehörten ${ }^{38}$.

Allerdings hatte der Reichstag beschlossen, in der Sache der Trois-Évêchés eine Gesandtschaft an den französischen Hof zu schicken. Die Antwort des Königs folgte der bereits etablierten Linie, sie war freundlich, aber inhaltslos. Auch in weiteren Verhandlungen wurde stets betont, daß es doch keinen Anlaß zur Beschwerde gebe, da der französische König die Reichszugehörigkeit der Hochstifte durch seine Protektion nicht beeinträchtigt habe. Im übrigen forderte der König, die Frage der Trois-Évêchés doch vor dem Reichstag zu verhandeln ${ }^{39}$. Wieder prallten die ohnehin schwachen Bemühungen von Seiten des Reiches an der Hinhaltetaktik Frankreichs einfach ab.

Bei der Kaiserwahl Maximilians II. im Jahr 1562 wurde das Thema der Trois-Évêchés erneut angesprochen, und man forderte, der neue Kaiser solle darauf bestehen, daß sich der französische König endlich zur Frage der Restitution äußere ${ }^{40}$. Doch trotz der Schwächung Frankreichs durch die Religionskriege konnte auch in den folgenden Jahren kein Erfolg erreicht werden. Die Bemulhungen von kaiserlicher Seite waren eher halbherzig. Und Spanien, das durch seine Besitzungen in Luxemburg und den Niederlanden ein besonderes Interesse an einem Rückzug der französischen Garnison aus Metz hatte, unternahm aufgrund der offiziellen Annäherung an Frankreich ebenfalls vorerst keine entsprechenden Anstrengungen ${ }^{41}$.

Nach 1565 ist wieder eine gewisse Intensivierung des kaiserlichen Interesses an den Trois-Évêchés zu beobachten: In diesem Jahr traf in Metz ein Schutz-

\footnotetext{
${ }^{35} \mathrm{Vgl}$. die Beratungen ibid. Bd. 3,2, S. 602-606.

${ }^{36}$ Ibid. Bd. 3,3, S. 1948.

${ }^{37}$ Vgl. hingegen MOHR, Lothringen, Bd. 4, S. 200, der auf dem Reichstag von 1559 ein ausgesprochenes Streben nach Rückerwerbung der drei Bistümer festgestellt haben will.

${ }_{38}$ RTA, Reichsversammlungen, Bd. 3,1, S. 511f. und Bd. 3,2, S. $798 f$.

${ }^{39}$ ZELLER, Réunion, Bd. 2, S. 56-58.

${ }^{40}$ Ibid. S. 59 f.

${ }^{41}$ Ibid. S. 60-66.
} 
brief des Kaisers Maximilian II. ein ${ }^{42}$. Dieser wandte sich auch in der Frage der Appellation am Reichskammergericht an den Bischof von Verdun, um die Berufungssumme bei Verfahren vor bischöflichen Gerichten wie bei Verfahren vor Gerichten des Domkapitels auf 500 rheinische Gulden zu begrenzen ${ }^{43}$. Zum Reichstag von 1566 waren erstmals seit 1552 auch wieder offizielle Vertreter der Bischöfe entsandt worden. Der Reichstag empfing diese jedoch keineswegs mit offenen Armen, sondern beriet im Gegenteil zunächst, ob man sie überhaupt zu den Beratungen zulassen könne. Schließlich gestand man den Vertretern der Bischöfe nur ein Teilnahmerecht für die allgemeinen, nicht aber für die geheimen Sitzungen $\mathrm{zu}^{44}$. Allerdings wollten diese sich auch keineswegs uber die französische Besatzung, sondern vielmehr über die Steuerveranlagung in der Reichsmatrikel beschweren ${ }^{45}$. Der König von Frankreich hatte hingegen trotz seines Versprechens keine Abgesandten geschickt, um über die Trois-Évêchés zu verhandeln. Im Reichstagsabschied wurde deshalb lediglich erklärt, die Stände hofften, daß der Kaiser die richtigen Wege finde, die territoriale Unversehrtheit des Reichs zu bewahren ${ }^{46}$.

Auf dem Reichstag von 1570 wiederholte sich das Szenario von 1566. Die Stimmung gegenüber den Vertretern der Bischöfe von Metz und Toul sowie der Stadt Verdun, die man bezichtigte, mit Frankreich gemeinsame Sache zu machen, war denkbar schlecht. Im Fürstenrat zog das Gesuch der Metzer Vertreter, auf Latein votieren zu dürfen, eine gereizte Diskussion um die Rolle des Bischofs bei den Ereignissen im Jahr 1552 nach sich und führte schließlich zum Beschluß, die Gesandten von allen Beratungen zur Restitutionsfrage auszuschließen ${ }^{47}$. Zugleich wurde im Städterat beraten, ob die Verduner Gesandten zugelassen werden könnten dweil bei inen allerhand vermutung gewest und noch, das die von Verdun dem Konig von Franckhreich mochten zugethan $\operatorname{sein}^{48}$. Den Suppliken aus Metz und Toul, die eine Erleichterung der Steuerlast für ihre Hochstifte forderten, wurde nicht stattgegeben ${ }^{49}$. Die Stadt Verdun betreffend wurde beschlossen, über die Verhältnisse vor Ort genauere Erkun-

${ }^{42}$ BnF, Dupuy 334, fol. 41-43 (5.6.1565).

${ }^{43}$ A.C. Verdun AA 3; BnF, N.a.fr. 7101, fol. 81-88.

44 Die im Jahr 1566 gefaBten Beschlüsse und Vorbehalte werden bei den Beratungen auf dem Reichstag von 1570 teilweise referiert, vgl. RTA, Reichsversammlungen 1556-1662. Bd. 1, Der Reichstag zu Speyer 1570. Bearb. v. Maximilian LANZINNER, 2 Teilbände Göttingen 1988, hier Bd. 1,1, S. 425.

${ }^{45}$ ZELLER, Réunion, Bd. 2, S. 69.

${ }^{46}$ RTA, Reichsversammlungen, Bd. 1,1, S. 425. Vergleiche auch Maximilian LANZINNER, Dietmar HEIL, Der Augsburger Reichstag 1566. Ergebnisse einer Edition, in: Historische Zeitschrift 274 (2002) S. 603-632, hier S. 611.

${ }^{47}$ RTA, Reichsversammlungen, Bd. 1,1, S. 424-431.

${ }^{48}$ RTA, Reichsversammlungen, Bd. 1,1, S. 582-585, 616 f.

${ }^{49}$ Suppliken Toul: RTA, Reichsversammlungen, Bd. 1,2, S. 1117 und Metz: ibid. S. $1051 \mathrm{f}$., 1067. 
digungen einzuziehen. Offenbar schenkte man der Beteuerung, man habe nur dem Kaiser einen Treueid geleistet, sei keinem anderen Herrscher verpflichtet und gerne bereit, die Pflichten und Lasten des Reiches mitzutragen ${ }^{50}$, nur wenig Vertrauen. Die Stadt Straßburg wurde aufgefordert, ein Gutachten zu erstellen, wie es mit der statt Verdun und darin erbautter vestung, auch dern und der statt Verdun besetzung und bewahrung ein gestalt habe, sonderlich auch, $o b$ solche statt der röm. kaiserl. Majestät pflichten und des hl. Römischen Reich allein, dem kinig in Franckhreich aber pflichten und aydt gar nit verwandt und underworffen; dergleichen ob höchstermelter kinig ainige und wes für bevelchhaber in gemelter stättrath haben, und ob er derselben statt mechtig seie oder nit $^{51}$. Wie zwiespältig die Haltung des Reichs gegenuber den lothringischen Städten und Stiften war, zeigt auch die Abrechnung der Türkenhilfe, auf der vermerkt ist, Metz. Tull, Verdun seindt frantzhösische und zalen nichts ${ }^{52}$, während gleichzeitig der Fiskalprokurator wegen der noch immer erfolgenden Nutzung des Reichskammergerichtes auf einer weiteren Steuerpflichtigkeit bestand ${ }^{53}$.

Erst 1582 ging eine neue Initiative zur Restitution von Seiten des spanischen Königs aus, da französische Truppen in den Niederlanden eingriffen und man sich von einem energischen Vorgehen des Reichs in Metz, Toul und Verdun eine gewisse Entlastung für die Situation in den Niederlanden versprach. Auch diese Initiative brachte jedoch kein Ergebnis ${ }^{54}$.

Obwohl man die Vertreter der Trois-Évêchés 1566 und 1570 nicht gerade mit offenen Armen auf den Reichstagen begrußt hatte, erfolgten auch weiterhin Einladungen zu den Versammlungen. Es scheint jedoch, daß diesen zumindest von Verdun aus nicht mehr nachgekommen wurde. So ist für 1595 eine Ladung überliefert, auf die der Magistrat ausweichend reagierte: Die Straßen seien zu unsicher, um eine Gesandtschaft zu schicken und was die Geldforderungen betreffe, habe man keinerlei Reserven mehr, da man sich die Neutralität während der Religionskriege, mit der man die Treue zum Reich bewahrt habe, teuer erkaufen mußte ${ }^{55}$. Der Touler Bischof hingegen entsandte noch 1594 und 1595 Vertreter zu den Reichstagen ${ }^{56}$.

Ohne einen militärischen Einsatz zu erwägen, versuchte die kaiserliche Diplomatie auch in den folgenden Jahren sporadisch, aktiv in die politischen und militärischen Verhältnisse der Trois-Évêchés einzugreifen. Insbesondere nach dem Tod des französischen Königs Heinrichs IV. im Jahr 1610 schien der Kai-

\footnotetext{
${ }^{50}$ Supplik der Stadt Verdun: ibid. Bd. 1,2, S. 1087 f.

${ }^{51}$ Abschied v. 1570: ibid. Bd. 1,2, S. 955.

${ }^{52}$ Ibid. Bd. 1,2, S. 793.

${ }^{53}$ Ibid. Bd. 1,2, S. 910.

${ }^{54}$ ZELLER, Réunion, Bd. 2, S. $73 \mathrm{f}$.

${ }^{35}$ Pettrot-BELlavène, Deux siècles, S. 218.

${ }^{56}$ KAUFMANN, Lothringische Geschichte, S. 48.
} 
ser wieder verstärkt tätig zu werden. So hatte der Bischof von Toul im September 1611, möglicherweise auf Drängen des Kaisers, diesem den Treueid angeboten und um Investitur ersucht. Der entsprechende Brief wurde jedoch nie abgesendet, offenbar weil die Vertreter des französischen Königs in Toul dies verhindern konnten ${ }^{57}$. Das entschlossenere Auftreten der königlichen Amtsträger zeigte sich im Jahr 1606 auch in Verdun, als Gouverneur und lieutenant du roi einen Gesandten des Kaisers mit Waffengewalt aus der Stadt jagten, bevor der Magistrat erfahren konnte, was dessen Anliegen war ${ }^{58}$. Dieses Vorgehen der Vertreter des französischen Königs vor Ort machte es wohl auch unmöglich, einer weiteren Ladung zum Reichstag nachzukommen, die 1612 bei Magistrat und Domkapitel von Verdun eintraf ${ }^{59}$.

Das 1607 nicht unter die Gerichtsbarkeit des président genommene und auch sonst weitgehend unabhängige Hochstift Metz stand auch wegen seiner Grenzlage am ehesten im Blickpunkt der kaiserlichen Aufmerksamkeit: 1613 hatte der französische Gouverneur von Metz, der Herzog von Épernon, per königlicher lettre auch das Gouvernement über das Hochstift mit seinen zahlreichen, strategisch wichtigen Festungen erhalten. Als er Truppen nach Vic verlegen wollte, traf er auf den Widerstand der bischöflichen Würdenträger, die den Kaiser zur Hilfe riefen. Dieser schickte einen außerordentlichen Botschafter, Johann Georg von Hohenzollern, nach Paris, der bei einem Zwischenstopp in Vic die Ständeversammlung des Hochstifts einberufen ließ und sie dazu brachte, den bereits im Januar 1614 geleisteten Treueid auf den französischen König zu widerrufen. Hohenzollern hatte auch in Paris Erfolg und konnte damit eine Ausweitung von Épernons Gouvernement vorerst stoppen ${ }^{60}$.

Mit Richelieu und dessen neuer Politik, sowie der sich nach 1625 allmählich wieder festigenden Stellung des Kaisers bahnten sich erneut Konflikte an. Vor allem die Kommission Cardin Le Brets, die von kaiserlicher Seite offenbar nicht ganz zu Unrecht als Vorbereitung zu einer Parlamentserrichtung gedeutet wurde, rief die Wiener Diplomatie auf den Plan: Im August 1625 wandte sich Kaiser Ferdinand II. an den Bischof von Metz, um ihn vor der Errichtung eines Parlaments zu warnen ${ }^{61}$. Der französische König Ludwig XIII. wurde angeschrieben ${ }^{62}$, die bischöflichen Vasallen ${ }^{63}$, und im Oktober erneut der Bischof von Metz selbst ${ }^{64}$, immer mit dem deutlichen Verbot, die Grenzen des

\footnotetext{
${ }^{57}$ Pimodan, Réunion, S. 359-361.

${ }^{58}$ A.C. Verdun, BB 4 (1606).

${ }^{59}$ BnF, N.a.fr. 7101, fol. 391-393.

${ }^{60}$ CABOURdin, Histoire, Bd. 3,1, S. 159.

${ }^{61} \mathrm{BnF}$, Dupuy 334, fol. 61 (4.8.1625).

${ }^{62}$ Ibid. fol. 56 (11.8.1625) an den König.

${ }^{63}$ Ibid. fol. 59 (18.10.1625) an die Vasallen.

${ }^{64}$ Ibid. fol. 58 (18.10.1625) an den Bischof.
} 
Reiches zu verändern (sacri imperii limites moveri) ${ }^{65}$ und der Erinnerung an die Vasallenpflicht des Bischofs und seiner Lehnsmänner. Dazu wurde der Bischof ermahnt, den noch ausstehenden Treueid beim Kaiser zu leisten. Auch die Vasallen wurden unter Androhung des Verlustes all ihrer Privilegien und Gerichtsrechte gebeten, »ernsthaft und beständig in Ergebenheit und Gehorsam gegenüber Kaiser und Heiligem Römischem Reich zu bleiben, ohne sich auf welche Art und Weise auch immer beirren oder verführen zu lassen ${ }^{66}$.

Zum letzten Mal kam es in den Trois-Évêchés anläßlich des Konflikts zwischen dem französischen Gouverneur und dem Bischof von Verdun zu Interventionen von Seiten des Reiches. Der Verduner Bischof François de Lorraine war aufgrund der Auseinandersetzung mit dem Gouverneur nach Köln geflüchtet und hatte dort gleich nach seiner Ankunft den Kaiser um Unterstiutzung gebeten. Die darauf folgende Enteignung des Bischofs durch den französischen König verursachte trotz des Krieges im Reich einen regelrechten Skandal ${ }^{67}$. Um die Jahreswende trafen empörte Briefe der Kurfürsten und des Kaisers beim französischen König ein, in denen der Ausschluß kaiserlicher Untertanen von kirchlichen und weltlichen Ämtern in Verdun, die Unterdrückung der kaiserlichen Gerichtsbarkeit, der Bau der Zitadelle und das Abschlagen der kaiserlichen Wappen beklagt wurden ${ }^{68}$. Nur im letzten Punkt gab der französische König den Beschwerden aus dem Reich recht. Die Verantwortung für die restlichen Klagen schob er auf das Verhalten des Verduner Bischofs ${ }^{69}$.

Immer deutlicher zeigte sich in den folgenden Jahren die Involvierung Frankreichs in die Kriegshandlungen im Reich. Damit waren auch die Beteuerungen, die Besetzung der Trois-Évêchés beeinträchtige die Rechte des Reiches nicht, endgültig Makulatur geworden. Auch umgekehrt zeigt sich, daß man im Reich die Trois-Évêchés zunehmend als feindliches Gebiet ansah: Kaiserliche Truppen belagerten Anfang des Jahres 1630 die nominell ja eigentlich noch zum Reich gehörenden Festungen Vic und Moyenvic im Hochstift Metz, die sie schließlich auch einnehmen konnten ${ }^{70}$. Die Rückeroberung der Festungen Vic und Moyenvic durch französische Truppen im Winter 1631 trennte endgültig auch im Hochstift Metz das Band zum Reich.

\footnotetext{
${ }^{65}$ Ibid. fol. 56 (11.8.1625) an den König.

${ }^{66}$ Veuillier persister sincerement et constamment en la devotion \& obeissance de nous \& du Sainct Empire, sans vous laisser destourner et seduire par aucune imagination et persuasion en quelque facon ou par quelque maniere que ce soit - Übertragung der Autorin, vgl. ibid. fol. 59 (18.10.1625) an die Vasallen.

${ }^{67}$ PETITOT-BELlavènE, Deux siècles, S. 282-284.

${ }^{68}$ Brief der Kurfürstenversammlung an den König vom 11.11.1627: BnF, N.a.fr. 7101, fol. 425f. und Brief des Kaisers vom 12.1.1628: ibid. fol. 417-419.

${ }^{69}$ Antwort des Königs an den Kaiser, ibid. fol. $420 f$.

${ }^{70} \mathrm{Vgl}$. die Schilderung der Ereignisse bei CabouRdiN, Histoire, Bd. 3,1, S. 186.
} 
Bei späteren Zusammenkünften mit Diplomaten aus dem Reich verfolgte Frankreich im Grunde weiter die Politik, da $\beta$ man auf Forderungen bezüglich der Trois-Évêchés gar nicht mehr einging ${ }^{71}$ und bei den Verhandlungen zum Westfälischen Frieden in Münster war die Frage ohnehin nur noch von nachrangiger Bedeutung ${ }^{72}$. So wurde im Friedensvertrag von Münster eine schon seit beinahe einhundert Jahren bestehende Tatsache vertraglich festgelegt, nämlich daß die Oberherrschaft, die Landeshoheit und alle andern Rechte auf die Bistümer Metz, Toul und Verdun und die gleichnamigen Städte und die Gebiete jener Bistümer, namentlich Moyenvic, in derselben Weise, wie sie bisher zum Römischen Reiche gehörten, inskünftig der Krone Frankreich gehören und ihr auf immer und unwiderruflich einverleibt werden sollen ${ }^{73}$.

\section{Die Trois-Évêchés und das Reichskammergericht}

Als Reichsterritorien unterstanden die Trois-Évêchés prinzipiell der Reichsgerichtsbarkeit ${ }^{74}$. Wie Friedrich Battenberg anhand eines Verfahrens aus dem 15. Jahrhundert vor dem Reichshofgericht gezeigt hat, war die Stadt Metz vor 1552 durchaus im Koordinatensystem des Reichs verankert. Nach seinen Untersuchungen war gerade die Reichsgerichtsbarkeit dazu geeignet, in den Randbereichen des Reiches effektiv tätig zu werden ${ }^{75}$. Im folgenden soll vor diesem Hintergrund untersucht werden, ob und wie sich die Reichsgerichtsbarkeit nach der französischen Besetzung der Trois-Évêchés gegenüber den Maßnahmen der königlichen Verwaltung behaupten konnte. Da seit Beginn des 16. Jahrhunderts die Reichsgerichtsbarkeit in den Trois-Évêchés hauptsächlich mit dem Reichskammergericht assoziiert wurde, soll dessen Tätigkeit hier genauer betrachtet werden.

Die Zuständigkeit des Reichskammergerichtes erstreckte sich in erster Instanz auf alle Fälle von Reichslandfriedensbruch, auf Rechtsstreitigkeiten reichsunmittelbarer Stände oder Personen untereinander und auf Verfahren

${ }^{71}$ Vgl. die Instruktionen für französische Gesandte zur Kölner Konferenz in BnF, fr. 18897. fol. 161-166.

72 TISCHER, Französische Diplomatie, S. 268f.

${ }^{73}$ Friedensvertrag von Münster, § 70; nach DICKMANN, Geschichte in Quellen, Bd. 3, S. 350.

${ }^{74}$ Vgl. oben, Kap. 2.

${ }^{75}$ Friedrich BATTENBERG, Ein Folgeprozess zum Zunftaufstand in der Reichsstadt Metz von 1405. Ein Beitrag zu Stellung und Funktion der obersten Reichsgerichte im 15. Jahrhundert, in: DERS., Beiträge zur höchsten Gerichtsbarkeit im Reich im 15. Jahrhundert, Köln, Wien 1981, S. 82-194. 
zwischen diesen Reichsständen und ihren Untertanen. Durch das sich im 16. Jahrhundert entwickelnde Mandatsverfahren kam hierzu noch eine generelle Zuständigkeit in allen kritisch zugespitzten Konfliktsituationen. Weiterhin ergab sich aus dem Königsrecht eine - zumindest theoretische - Zuständigkeit für alle Angelegenheiten von Witwen, Waisen und Minderjährigen ${ }^{76}$. Die neben der Landsfriedenswahrung wichtigste Funktion des Reichskammergerichts war jedoch die Kontrolle der Gerichte der einzelnen Reichsstände, für die es das Berufungsgericht in allen Zivilsachen und Kontrollinstanz in allen Fällen von Rechtsverweigerung, Rechtsverzögerung sowie Nichtigkeitsklagen aufgrund grober Rechtsverstöße war ${ }^{77}$. Eine Berufung in Strafsachen war vor dem Reichskammergericht ausgeschlossen. Dies sollte später für die französische Politik und deren Argumentation in den Trois-Évêchés besondere Bedeutung erlangen ${ }^{78}$.

Die Errichtung des Reichskammergerichts im Jahr 1495 und insbesondere die damit verbundenen Kosten waren in den Trois-Évêchés wie im Herzogtum Lothringen auf wenig Zustimmung gestoßen. Die Klagen der drei lothringischen Bischöfe auf dem Reichstag von 1532 beispielsweise schlossen auch die Kosten der Reichsgerichtsbarkeit ein ${ }^{79}$. Doch nicht nur die Unterhaltung des Reichskammergerichts, auch die Prozesse dort waren kostspielig, denn sie konnten lange dauern und hohe Kosten für Advokaten, Übersetzer und anderes Personal mit sich bringen ${ }^{80}$.

Wie zahlreiche Landesherren im Reich strebten daher auch die Stadtregierungen und Bischöfe der Trois-Évêchés an, durch die Festlegung eines Mindeststreitwertes, ab dem Berufung in Speyer eingelegt werden konnte, oder gar

\footnotetext{
${ }^{76}$ Vgl. hierzu Adolf LAUFS, Art. »Reichskammergericht« in: Handwörterbuch für Rechtsgeschichte, hg. v. Adalbert ERLER, Ekkehardt KaUfmanN, Bd. 4, München 1988, Sp. 655-662, hier Sp. 659f. sowie Wolfgang SELLERT, Über die Zuständigkeitsabgrenzung von Reichshofrat und Reichskammergericht insbesondere in Strafsachen und Angelegenheiten der freiwilligen Gerichtsbarkeit, Aalen 1965 (Untersuchungen zur deutschen Staats- und Rechtsgeschichte, NF 4), S. 46-72.

${ }^{77}$ LAUFS, Reichskammergericht, Sp. 659f. sowie Gilbert CAHEN, Archives Départementales de la Moselle. Complément au répertoire numérique de la série $B$ (Cours et jurisdictions) Répertoire du fonds de la Chambre impériale de Spire et de Wetzlar (articles B 10720B11142), Metz 1974, S. 3.

${ }^{78}$ Die grundsätzliche Ablehnung einer Berufung in Strafsachen begründet SELLERT, Zuständigkeitsabgrenzung, S. 73f. weniger mit dem Unabhängigkeitsbestreben der Reichsstände als vielmehr mit dem Strafverfahren des Inquisitionsprozesses, der ohnehin kein Urteil ohne Geständnis vorsah.

${ }^{79} \mathrm{Vgl}$. den Text der Beschwerde bei WINKELMANN, Beiträge, S. 207-212.

${ }^{80}$ Die Klagen über die Langsamkeit und die hohen Kosten des Reichskammergerichtes sind Legion und hatten sich schon im 16. Jahrhundert verselbständigt. Es kann nicht Zweck dieser Arbeit sein, die breite Forschung zum Reichskammergericht zu referieren, deshalb sei hier nur zu einer ersten Orientierung genannt: Adolf LAUFS, Art. "Reichskammergericht» in: HRG, Bd. 4, Sp. 655-662, v.a. Sp. 655. Dort auch weitere Literatur.
} 
durch ein privilegium de non appellando die Verfahren aus dem eigenen Territorium möglichst gering zu halten und so die Finanzkraft der Untertanen zu bewahren ${ }^{81} .1550$ bemühte sich der Metzer Bischof bei Kaiser Karl V. darum, Berufungen aus dem Hochstift Metz vor dem Reichskammergericht erst ab einem Streitwert von 300 rheinischen Goldgulden zuzulassen. Der Kaiser hatte angeblich zwar einer solchen Begrenzung zugestimmt, das entsprechende Privileg jedoch nie abgesandt ${ }^{82}$. Auch der Rat der Stadt Metz betrieb zum gleichen Zeitpunkt die Erlangung eines solchen Privilegs. Die Berufungssumme, die man vom Kaiser zu diesem Zweck forderte, war deutlich höher: 1000 rheinische Goldgulden. Die Stadt hatte bei ihrem Ansinnen dennoch mehr Erfolg als der Bischof - der Kaiser stimmte dieser Begrenzung der Appellationssumme $\mathrm{zu}^{83}$.

Nach 1552 war man in den Trois-Évêchés weiterhin um eine Begrenzung der Appellationssumme bemüht. Das Hochstift Metz konnte durch seine Bemühungen 1563 einen Mindeststreitwert von 300 Goldgulden festlegen las$\operatorname{sen}^{84}$. In Verdun wurde 1566 (registriert 1567) die deutlich höhere Summe von 500 Goldgulden sowohl für Berufungen von bischöflichen (und damit auch städtischen) Gerichten, als auch für die Gerichte des Domkapitels gewährt ${ }^{85}$ und in Toul erreichten die bischöflichen Gerichte 1594 eine Begrenzung auf 450 Goldgulden ${ }^{86}$. In Bezug auf eine Begrenzung der Appelle vor dem Reichskammergericht argumentierte man also auch nach 1552 nicht mit einer faktischen Zugehörigkeit zu Frankreich, sondern wählte weiterhin den normalen "Geschäftsgang" des Reiches ${ }^{87}$.

Im Verhältnis zum Reichskammergericht zeigt sich ein deutlicher Unterschied zwischen der Haltung der Stadt Metz und der Position der übrigen, bischöflichen Territorien. In der Stadt Metz war man von Beginn an nicht bereit, Berufungen vor dem Reichskammergericht zu akzeptieren. Der Metzer Chronist Philippe de Vigneulles berichtet, daß bereits 1499 ein Kaufmann namens Collat, der vor dem Reichskammergericht appelliert hatte, von Soldaten des Magistrats nicht nur an der Ausreise nach Worms gehindert wurde, sondern

${ }^{81} \mathrm{Vgl}$. Jean-François NoËL, Les pays rheno-mosellans et la Chambre impériale de Justice (Reichskammergericht) 1500-1600, in: Théorie et pratique politique à la Renaissance, Paris 1977, S. 159-187, hier 176.

${ }^{82}$ A.D. Moselle, B 10958.

${ }^{83} \mathrm{Vgl}$. zum Verhältnis von Stadt und Reichskammergericht die Schilderung bei ZELLER, Réunion, Bd. 1, S. 236-240.

${ }^{84}$ A.D. Moselle, B 10958.

${ }^{85}$ A.D. Moselle, B 11086 und B 11087.

${ }^{86}$ A.D. Moselle, B 11075.

${ }^{87} \mathrm{Vgl}$. ähnlich auch NOËL, Chambre imperiale, S. 168. 
auch mit einer Gefängnis- und Geldstrafe belegt wurde ${ }^{88}$. Auch ein Schwager des Chronisten, so berichtet dieser weiter, mußte 1502 ins Gefängnis, nachdem er vor dem Reichskammergericht Berufung gegen ein Urteil des Schöffenmeisters eingelegt hatte ${ }^{89}$.

1548 hatte ein Kläger aus Metz erstmals Erfolg und das Reichskammergericht nahm sich seiner Klage an. Das Appellationsprivileg, das die Stadt kurz darauf erlangte, hielt aber die Anzahl der Berufungen gering. Gleichzeitig versuchte man in Metz auch weiterhin, mit Gefängnisstrafen gegen Bürger vorzugehen, die ans Reichskammergericht appellierten ${ }^{90}$.

Die bischöfliche Gerichtsbarkeit des Hochstifts Metz in Vic akzeptierte hingegen die Urteile aus Speyer, was sich unter anderem auch daran zeigt, daß diese manchmal sogar in die Urteilsbücher des Bailliage-Gerichtes aufgenommen wurden ${ }^{91}$. Auch in Verdun war die Autorität des Reichskammergerichts offenbar weitgehend unbestritten. So beschloß der Stadtrat 1575 wegen einer Vakanz des Bischofsstuhls, die Berufungen der städtischen Gerichte statt vor das bischöfliche Gericht direkt vor das Reichskammergericht gehen zu lassen ${ }^{92}$.

Besonders in der Diskussion um die Ausweitung der Kompetenzen des vom König eingesetzten président in Metz auf die Städte Toul und Verdun wird deutlich, welche Argumente zur Reichskammergerichtsbarkeit in den lothringischen Territorien in der zweiten Hälfte des 16. Jahrhunderts kursierten. Diese Diskussion soll später noch einmal ausführlich besprochen werden. Um sie jedoch beurteilen zu können, scheint ein Blick auf den tatsächlichen Umfang und die Art der Verfahren aus den Trois-Évêchés vor dem Reichskammergericht unerläßlich.

\section{Die Verfahren vor dem Reichskammergericht}

Noch immer ist die Frage des Metzer Archivars Vidier von 1928 in großen Teilen unbeantwortet: »A quelle occasion, dans quelles conditions et jusqu'à quelle époque les justiciables ont-ils porté leurs affaires en dernière instance

\footnotetext{
${ }^{88}$ Philippe de Vigneulles in: Jean François HuguemIN (Hg.), Les chroniques de la Ville de Metz recueillies, mises en ordre et publiées pour la première fois (900-1552), Metz 1838, S. 630 .

${ }^{89}$ Vigneulles in: Huguemin, Chroniques, S. 639.

${ }^{90}$ ZELLER, Réunion, Bd. 1, S. 237.

${ }^{91}$ A.D. Meurthe-Mos. BJ 1476 (1615), fol. 3.

${ }^{92}$ A.C. Verdun BB 1 (1575).
} 
devant la Haute Cour de l'Empire? ${ }^{93}$ Dabei scheinen der tatsächliche Umfang der in Speyer geführten Verfahren, die Herkunftsorte der Kläger und der Zeitpunkt der Klagen ein ideales Mittel zu sein, um die »Reichsnähe« dieser Territorien besser beurteilen zu können ${ }^{94}$. Dies gilt um so mehr, da die Berufungen vor dem Reichskammergericht zunehmend das einzig verbliebene Merkmal der Reichssouveränität waren, wie es 1608 in einer Beschwerde der Stände von Toul heißt: de toutes les marques de la Souveraineté de l'Empire il n'en reste que celle-la dedans Toul ${ }^{95}$.

Um Anhaltspunkte für die tatsächliche Klageaktivität aus den Trois-Évêchés zu erhalten, wurden mit Hilfe des Repertoriums die in den Archives départementales de la Moselle in Metz archivierten Reichskammergerichtsakten ausgewertet ${ }^{96}$.

Die Betrachtung der im Departementsarchiv von Metz überlieferten Verfahren ergibt für die drei Hochstifte und die Stadt Metz dabei ein sehr unterschiedliches Bild. Im folgenden wird deshalb unterschieden zwischen der Stadt und dem Hochstift Metz sowie den Verfahren aus Toul und Verdun, bei denen durch die Organisation der Gerichtsbarkeit (bischöfliches Gericht war Berufungsinstanz für städtische Gerichte) nicht mehr zwischen Stadt und Hochstift unterschieden wurde. Die ausgesprochen geringe Zahl der Berufungen von den Gerichten der Domkapitel von Toul und Verdun läßt es zudem sinnvoll erscheinen, diese gemeinsam mit den übrigen Verfahren aus diesen Städten $\mathrm{zu}$ betrachten. Weiterhin wird im folgenden unterschieden zwischen Berufungen und solchen Verfahren, die von den Klägern in erster Instanz vor das Reichskammergericht getragen wurden und im Mandats- oder Zitationsverfahren behandelt wurden ${ }^{97}$.

\footnotetext{
${ }^{93}$ Vgl. CAHEN, Répertoire, S. 5.

${ }^{94} \mathrm{Vgl}$. die Arbeiten von NOËL, Chambre impériale, und Filippo RANIERI, Recht und Gesellschaft im Zeitalter der Rezeption. Eine rechts- und sozialgeschichtliche Analyse der Tätigkeit des Reichskammergerichts im 16. Jahrhundert, 2 Bde., Köln, Wien 1985 (Quellen und Forschungen zur höchsten Gerichtsbarkeit im Alten Reich, 17), S. 185f.

${ }_{95} \mathrm{BnF}$, Dupuy 124, fol. 244, auch BnF, N.a.fr. 16889, fol. $289 f$.

${ }^{96}$ CAHEN, Répertoire. Im Rahmen der vorliegenden Arbeit kann jedoch eine umfassende Analyse der Verfahren vor dem Reichskammergericht nicht geleistet werden, da aufgrund des Umfangs des Quellenbestandes weder eine umfassende Einsicht in die Originalakten noch eine Einbeziehung der nicht in den A.D. Moselle konservierten Dokumente möglıch war. $\mathrm{Da}$ keineswegs alle aus den Trois-Évêchés angestrengten Verfahren durch die in Metz konservierten Akten überliefert sind, zeigt sich an Funden von zahlreichen weiteren in der Literatur oder anderen Quellen überlieferten Verfahren. Vgl. nur als ein Beispiel das aus den Stadtratsprotokollen überlieferte Verfahren zwischen Domkapitel und Magistrat in Verdun 1573/1574, PETITOT-BeLlaVĖNE, Deux siècles, S. 155. Vgl. auch die unten genannten Verfahren aus Metz: Pelletier gg. Praillon und Roucel gg. Sauvage.

${ }^{97}$ Vgl. zum Verfahren vor dem Reichskammergericht Wolfgang SELLERT, Art. "Prozeß des Reichskammergerichts« in: HRG, Bd. 4, Sp. 29-36 und M. HINZ, Art. »MandatsprozeB«, in: ibid. Bd. 3, Sp. 233-240.
} 


\subsection{Stadt Metz}

Wie überall in den Trois-Évêchés begannen auch in Metz die Kläger erst Mitte des 16. Jahrhunderts, ihre Verfahren vermehrt vor das Reichskammergericht zu tragen. In Metz sind vor dem Jahr 1546 ausschließlich erstinstanzliche Verfahren überliefert. Zwei frühe Berufungen konnten aus den Jahren 1546 und 1548 gefunden werden. Kurz vor der französischen Besetzung, insbesondere zwischen 1550 und 1551 kann dann ein geradezu sprunghaftes Ansteigen der Appelle vor dem Reichskammergericht konstatiert werden. Deren Zahl stieg allein im Jahr 1550 auf sieben an, im Jahr 1551 kamen sechs weitere hinzu ${ }^{98}$. Daneben finden sich ein halbes Dutzend erstinstanzliche Verfahren aus den Jahren 1548 und $1550^{99} .1552$ ebbte diese Welle wieder ab. Zeller vermutet hier einen Zusammenhang mit der weitgehenden Entmachtung der patrizischen Stadtregierung nach der französischen Besetzung, durch den der häufig gegen die städtischen Gerichte geäußerte Vorwurf einer parteiischen Patrizierjustiz entkräftet wurde ${ }^{100}$. Gegen diese Vermutung spricht jedoch die Tatsache, daß die 1550-1551 eingelegten Berufungen eher von Personen aus der städtischen Oberschicht selbst angeregt wurden, als von solchen Personen, die die städtischen Richter oder allgemein Angehörige der Patrizierfamilien anklagen wollten $^{101}$.

Aus den Jahren nach der Besetzung sind in den Dokumenten des Departementsarchivs in Metz kaum Appelle von städtischen Gerichten aus Metz nach Speyer erhalten: Zwei Verfahren wurden 1552 begonnen, drei weitere in den Jahren 1560,1563 und $1584^{102}$. Bemerkenswert ist bei den beiden letzten Verfahren, daß sie zwar noch Berufungen von städtischen Gerichten waren, aber nicht mehr von Bewohnern der Stadt eingelegt wurden ${ }^{103}$. Wie unvollständig der Bestand ist, zeigt sich an der Tatsache, daß der Beginn zweier weiterer Prozesse (von Androuin Roucel gegen Mengin Sauvage und von Pierre Pelle-

${ }^{98}$ Für 1550: A.D. Moselle, B 11046, 10850, 10842, 10825, 10800, 10736, 10746; für 1551: Ibid. B 10749, 11043, 11033/1, 10947, 10758, 10843.

${ }_{99}$ Ibid. B 10951, 11073, 11034, 10952, $11062,10953$.

${ }^{100}$ ZELLER, Réunion, Bd. 2, S. 147.

${ }^{101}$ So finden sich als Vertreter der wichtigsten Familien von Metz zweimal Claude de Gournay, Sieur de Talange, A.D. Moselle B 10842 und 10843; Margarethe de Brandenbourg, Witwe v. Nicolas d'Heu, Sieur d'Ennery, B 10746; Androuin Roucel, Seigneur d'Aubigny, B 11043. Gleichzeitig Klagen gegen Michel de Gournay (von Étienne Barbier, "pauper«) B 10736; gegen die Treize de Metz: B 10749, und ein Mandatsverfahren von G. Thierry gegen maître-échevin und Treize B 11073.

${ }_{102}$ Ibid. B 10741, 10939, 11025,10965 und 10883.

${ }^{103}$ Einmal war der Appellant in Saint-Avold ansässig (ibid. B 10965), einmal in Luxemburg (B 10883). 
tier gegen Michel Praillon) in den Akten der städtischen Institutionen, nicht aber im Bestand der Reichskammergerichtsakten überliefert is $t^{104}$.

Soweit dies die kursorische Sichtung der Akten und Findbücher ergeben hat, war der Personenkreis, der aus Metz das Reichskammergericht angerufen hat, weitgehend inhomogen. Bereits genannt wurde der relativ hohe Anteil von Angehörigen der patrizischen Führungsschicht. Ebenfalls stark vertreten, insbesondere in den erstinstanzlichen Verfahren, waren kirchliche Institutionen $^{105}$. Eine weitere häufig genannte Personengruppe sind Kaufleute ${ }^{106}$. In Appellationsverfahren wurden hauptsächlich schuld- und erbrechtliche Angelegenheiten verhandelt, in erstinstanzlichen Verfahren vor allem die typischen Fragen des Landfriedensbruchs und des Angriffs auf kaiserlich garantierte Bestimmungen oder Privilegien.

Die geringe Anzahl von Berufungen nach 1552 läßt sich vor allem durch die Tätigkeit des président erklären. So schlichtete dieser 1554 den Prozeß der Claudette le Pelletier gegen Jacques de Remich, die ihm versprechen mußten, von ihrer Berufung in Speyer zurückzutreten ${ }^{107}$. Wie bereits betont, vertraten hierbei der Magistrat der Stadt und der président als Amtsträger des französischen Königs ganz ähnliche Interessen. Gaston Zeller verdeutlicht die Haltung der Stadt Metz an zwei Fällen: 1553 vollstreckte das städtische Gericht der Dreizehn ein Urteil, obwohl Berufung vor dem Reichskammergericht eingelegt worden war ${ }^{108}$. Im zweiten Fall aus dem Jahr $1560^{109}$ bekamen nicht die Beteiligten selbst, sondern der Bote des Reichskammergerichtes die Abneigung von Magistrat und königlichen Vertretern gegen solche Berufungen zu spüren. Das Protokoll der Ereignisse, das der Bote Lorenz Alagawer angefertigt hat, zeigt deutlich das Zusammenwirken von Stadtrat und königlichen Vertretern. Der Bote wurde nach mehreren Tagen Hinhalten vom königlichen Gouverneur in Anwesenheit des président, des amtierenden und des zukünftigen Schöffenmeisters, sowie zahlreicher Ratsmitglieder aufs heftigste bedroht und beschimpft. So habe ihm der Gouverneur mit einem finger gedreit er sag mir nit mehr: wo ich mich mit einem geringsten bustaben lass mercken, so sol ich abermal leip und leben verfallen sein ${ }^{110}$.

\footnotetext{
${ }^{104}$ Nach ZeLLER, Réunion, Bd. 2, S. 147.

${ }^{105}$ Domkapitel v. Metz A.D. Moselle B 10951 und 10957, Abt und Konvent von SaintVincent B 10952, und 10953, Abt v. Staint-Symphorien B 11062. Appell von N. Vincey, Kommandant des Antonistenhospizes, B 11093.

${ }^{106}$ Ibid. B 10825, 10800, 11033/1, 10947, 10741, 10939.

${ }^{107}$ ZELLER, Réunion, Bd. 2, S. 148f., die Akten des Reichskammergerichts in A.D. Moselle, B 11033/1.

${ }^{108}$ ZELLER, Réunion, Bd. 2, S. 148 (Anm., Kläger war Androuin Roucel).

${ }^{109}$ Richard de Raigecourt gegen die Erben des Pierre Cron. Vgl. die Akten des Reichskammergerichts A.D. Moselle, B 11025.

${ }^{110}$ Der Bericht des Lorenz Alagawer ist abgedruckt bei ZeLLER, Réunion, Bd. 2, S. 331-333.
} 
Die üble Behandlung Alagawers hatte sich offenbar auch im Reich herumgesprochen, denn im Jahr 1610 verweigerte ein Kammergerichtsbote die Zustellung in Metz, weil, der Appelat Christoff Hanssen Sei ein Burger zu Metz, die weil die stat Metz der Cron Franckreich wider werffen unnd Kainem Cam(m)erbotten gestatt würd, daselbsten Proceß zu Insinuiern ${ }^{111}$.

\subsection{Hochstift Metz}

Nach 1552 hatten, wie oben gezeigt, die Berufungen aus der Stadt Metz praktisch aufgehört. Im Hochstift Metz, in Toul und Verdun hingegen lagen die Verhältnisse anders, da der königliche président hier zunächst keinerlei Befugnisse hatte. Aus diesem Grund sollten sich dort die Appelle vor dem Reichskammergericht noch bis 1607, beziehungsweise im Hochstift Metz bis 1633 fortsetzen.

Ebenso wie in der Stadt setzten auch im Hochstift Metz die Berufungen erst spät, d.h. nach 1530 ein, also nach einer gewissen Konsolidierungsphase des Kammergerichtes und seiner Installation in Speyer. Obwohl die Anzahl der Verfahren mit durchschnittlich etwa zwei bis drei neuen Prozessen pro Jahr deutlich die Anzahl der Verfahren unterschreitet, die aus dem Hochstift in den ersten Jahrzehnten des 16. Jahrhunderts vor dem städtischen Appellationsgericht des Schöffenmeisters festgestellt wurden ${ }^{112}$, liegt sie mit insgesamt 174 Appellationen und zwölf erstinstanzlichen Verfahren noch immer deutlich höher als die der Verfahren aus Toul (23 und 6) oder Verdun (18 und 8) ${ }^{113}$.

Betrachtet man den Zeitpunkt der einzelnen Prozesse, so zeigt sich eine relativ gleichmäßige Verteilung über die Jahre 1550-1631. Nur zwei Phasen fallen ein wenig aus diesem Bild: Besonders viele Verfahren vor dem Reichskammergericht wurden im Hochstift Metz in den Jahren 1554-1564 begonnen (4,2 pro Jahr gegenüber durchschnittlich 2,3), besonders wenige in der Amtszeit des Bischofs Kardinal Charles II de Lorraine, den Jahren 1586-1607 (etwa 1,2 Verfahren pro Jahr). Dies macht bereits deutlich, wie wenig die französische Rechtspolitik hier zunächst bewirken konnte: Die Hochphase des

${ }^{111}$ HStA Wiesbaden, Bestand 1, 3075,1v. Ich möchte Andreas Göller für den freundlichen Hinweis herzlich danken.

${ }^{112}$ Die Auswertung basiert auf einer Auszählung der jeweiligen Verfahren auf der Grundlage des Repertoriums von Cahen zu den Reichskammergerichtsprozessen und der Sammlung von SALVERDA DE GRAVE, MEIJERS, SChNEIDER, Droit Coutumier, Bd. 3 zu den Verfahren vor dem maître-échevin.

${ }^{113}$ Die Zahlen wurden, wie alle Angaben, anhand des Repertoriums von Cahen ermittelt. Zusammenhängende Verfahren, bei denen in der gleichen Sache von der gleichen Partei zwei Berufungen eingelegt wurden, wurden hierbei als eines gezählt. Aufgrund der großen Zahl an Verfahren kann im folgenden nur im Einzelfall die genaue Signatur angegeben werden. Auch hier sei auf das o.g. Repertorium, das über ein gutes Register verfügt, verwiesen. 
Reichskammergerichts im Hochstift Metz beginnt ausgerechnet mit der $\mathrm{Er}$ nennung eines königlichen président in Metz, der eben diese Verfahren zu verhindern suchte. Sie ebbt erst nach Erteilung des kaiserlichen Appellationsprivileges, das einen Mindeststreitwert von 500 rheinischen Goldgulden festlegte, $a b^{114}$. Die geringste $Z$ ahl an Berufungen und erstinstanzlichen Klageschriften wurden hingegen nicht unter einem relativ königsnahen $\mathrm{Bi}$ schof wie Henry de Bourbon eingereicht, sondern unter Kardinal Charles II de Lorraine, einem entschiedenen Gegner der königlichen Politik und innenpolitisch starken Bischof.

Betrachtet man die Kläger, wird neben der relativen Unabhängigkeit des Territoriums noch ein weiterer Grund für die hohe Zahl an Verfahren aus dem Hochstift Metz deutlich. Ein beträchtlicher Teil der Kläger (mindestens ein Drittel) waren nämlich Lehnsmänner oder Untertanen des Bischofs aus dem relativ kleinen deutschsprachigen Teil des Herrschaftsgebietes ${ }^{115}$. Relativ hoch ist allgemein der Anteil adliger Kläger und entsprechend - neben den auch in der Stadt Metz häufigen schuld- und erbrechtlichen Verfahren - der Anteil der lehnsrechtlichen Auseinandersetzungen ${ }^{116}$. Ebenfalls ein beträchtlicher Teil der Berufungen bezieht sich auf Beleidigungsklagen, die eher von bürgerlichen Klägern angestrengt wurden und in die häufig Amtsträger des BailliageGerichts in Vic oder untergeordneter Gerichte involviert waren ${ }^{117}$. Daneben fallen Gemeinden als Kläger, aber auch als Angeklagte, ins Auge - meist in Auseinandersetzungen um Weide- bzw. Herrschaftsrechte ${ }^{118}$.

${ }^{114}$ ZeLLER, Réunion, Bd. 2, S. 208. Nach Ausweis des Repertoriums der Reichskammergerichtsakten von Cahen ließ Charles jedoch nur durch Ferdinand ein Privileg bestätigen, das bereits Karl V. bewilligt hatte - allerdings nur über die Summe von 300 Goldgulden. Vgl. CAHEN, Repertoire, Eintrag B 10958.

${ }^{115} \mathrm{Ca}$. 62 von 186, wobei bei dieser kursorischen Zählung nur die Personen berücksichtigt wurden, die durch Appelle oder Klagen das Verfahren in Gang gebracht haben und entweder aufgrund ihres Namens, ihres Wohnortes oder ihres Titels relativ eindeutig als deutschsprachig identifiziert werden konnten. Die tatsächliche Zahl mag deshalb noch wesentlich höher gelegen haben.

${ }^{116}$ Hier fallen vor allem die Verfahren der Claude de Dommartin, Witwe des Philipp von Dhaun, um Réchicourt und Falkenstein (A.D. Moselle, B 10780 und 10784-10789) sowie der Herren von Eberstein (B 10792-10798), Leiningen (B 10891-10925), Nassau-Saarbrucken (B 10989-11001), sowie der Herren von Créhange/Kriechingen (B 11118-11132) ins Auge.

${ }_{117}$ Solche Fälle waren ibid. B 10734, 10856, 11019, 10804, 10839, 10834, 10889, 11096, 10998; einfache Beleidigungsfälle: B 10769, 11011, 11032, 10725, 11007, 11069/1, $11069 / 2,10882,10833,10759$.

118 Verfahren, die von Gemeinden eingeleitet wurden: ibid. B 11033/2, 108929, 10963, 10846, 11111, 10815, 10757, 11117, 10791, 11055, 10946, 10959, 10927, 10926, 10799. 11027,10935 . $\mathrm{Zu}$ Gemeinden als Klăger vor dem Reichskammergericht vgl. Winfried SCHULZE, Băuerlicher Widerstand und feudale Herrschaft in der frühen Neuzeit, Stuttgart 1980 (Neuzeit im Aufbau, 6). Im Hochstift Metz wurde allerdings die Mehrzahl der Prozesse von Gemeinden gegen Nachbargemeinden und nicht gegen die Grundherren angestrengt. 


\subsection{Verdun}

Ähnlich wie im Hochstift Metz traf auch aus Verdun ein Großteil der Appelle vor dem Reichskammergericht in den Jahren von 1558-1566 ein (12 von 18 Verfahren insgesamt), während die erstinstanzlichen Verfahren meist früher datieren ${ }^{119}$. In der Zeit nach 1552 übte der Bischof in Verdun zunächst ein relativ eigenständiges Regiment aus, in dem er vermehrt Zugriff auf die städtischen Institutionen nahm. Die Organisation der Gerichtsbarkeit in Verdun bedingte, da $B$ Berufungen gegen Urteile der städtischen Gerichte und des bischöflichen Bailliage-Gerichts zunächst vor das bischöfliche Gericht der chambre épiscopale getragen wurden, bevor eine Berufung vor dem Reichskammergericht angestrengt werden konnte. Dementsprechend machen die Berufungen gegen Urteile der chambre épiscopale einen Großteil der Verfahren aus. Von den unabhängigen Gerichten aus dem Territorium des Verduner Domkapitels wurde nur eine Klage vor das Reichskammergericht getragen ${ }^{120}$. Ebenfalls deutlich wird der Zusammenhang zwischen der Erteilung des kaiserlichen Appellationsprivilegs im Jahr 1566 und dem Abebben der Verfahren vor dem Reichskammergericht.

Bezüglich der Verfahrensgegenstände und der sozialen Herkunft der Kläger wiederholen sich die für Metz gemachten Beobachtungen: Auch bei den Prozessen aus Verdun dominierten Erb- und Schuldrechtsverfahren, als Kläger finden sich Amtsträger aus Stadt und Umland, Kaufleute, eine Gemeinde und die Grundherren des Umlandes ${ }^{121}$. Ein Blick auf die erstinstanzlichen Verfahren zeigt jedoch eine Funktion des Reichskammergerichts, die in Metz weniger stark zutage getreten ist: Die Schlichterfunktion für innere Konflikte um Privilegien und Rechte zwischen Domkapitel, Bischof und Stadt. So findet sich schon im Jahr 1540 ein erstes Verfahren zwischen der Stadt Verdun und ihrem Bischof um die städtischen Gerichtsprivilegien ${ }^{122}$. Auch das Domkapitel

Häufiger war hier der Fall, daß Grundherren gegen die Gemeinden Verfahren vor dem Reichskammergericht angestrengt haben. Diese sind in der obigen Aufzählung nicht eingeschlossen.

${ }^{119}$ Appelle aus der Zeit 1558-1566: A.D. Moselle, B 10954, 10942, 10944, 10742, 10730, $10824,10729,10773,10950,10826,10829,10838$. Erstinstanzliche Verfahren wurden begonnen in den Jahren 1529 (B 10753), 1540 (11088), 1549 (11090), 1550 (11089), 1551 (11084), 1559 (11091), 1560 (11085) und 1561 (11059).

${ }^{120}$ Ibid. B 10730.

${ }^{121}$ Nicht immer finden sich neben dem Namen weitere Angaben über die Parteien. Als Kläger traten aber u.a. auf: Amtsträger (ibid. B 10776, 10826, 10829, 10767), Kaufmann (B 10942, 10944, 10773), eine Gemeinde (B 10730), und Grundherren (B 10824, 10729, $10950,10838,10855)$.

${ }^{122}$ Ibid. B 11088-1 1090. Vgl. zu diesem Verfahren AIMOND, Rélations, S. 366, 407f. 
trug im Jahr 1551 und 1559 seine Forderungen nach Immunität und Steuerfreiheit gegenüber der Stadtgemeinde vor das Reichskammergericht ${ }^{123}$.

Interessant ist weiterhin, da $B$ sich nach 1575 kaum Berufungen vor dem Reichskammergericht finden, obwohl der Stadtrat in diesem Jahr beschlossen hatte, daß während der Sedisvakanz des Bischofsstuhls alle Berufungen gegen Urteile der städtischen Gerichte statt vor den bischöflichen Gerichten direkt vor dem Reichskammergericht eingelegt werden sollten ${ }^{124}$. Die Entscheidung des Stadtrates von 1575 ist dennoch interessant: Sie zeigt, daß auch nach Jahren der französischen Besetzung in Verdun noch immer der Rückgriff auf eine Institution des Reiches gewählt wurde. Auch im Jahr 1576 ist die Bindung zum Reich noch deutlich erkennbar: Vertreter der Stadt nahmen am Reichstag in Regensburg teil, und zum Tod des Kaisers Maximilian wurde eine Totenmesse gelesen ${ }^{125}$. Aus den rund 10 Jahren der Ligabesetzung von Toul und Verdun nach 1585 finden sich aus Verdun keine Berufungen, während in der gleichen Zeit in Toul die Zahl der Verfahren auf dem - niedrigen - Niveau der Vorjahre bleibt. Insgesamt wurde also das Reichskammergericht kaum noch genutzt, während verstärkt Verfahren vor den conseil du roi und das Parlament von Paris getragen wurden ${ }^{126}$. Wie die Pariser Gerichte nach und nach das Reichskammergericht ersetzten, wird am Fall der bischöflichen prévôté Tilly deutlich. Dort weigerten sich die Bewohner 1572, ihren Beitrag zur Reichssteuer zu leisten - eigentlich ein klassischer Fall für ein Mandats- oder Zitationsverfahren vor dem Reichskammergericht. Der Bischof jedoch suchte seine Forderungen vor dem königlichen conseil privé durchzusetzen, während sich die Bewohner von Tilly an das Pariser Parlament wendeten ${ }^{127}$. Die Kompetenzerweiterung des königlichen président von Metz in den Jahren 1607 bzw. 1611 hatte hingegen auf die Nutzung des Reichskammergerichtes in Verdun keinen Einfluß mehr, da die letzte Klage aus Verdun bereits im Jahr 1600 eingereicht worden war.

\subsection{Toul}

In Toul wurde ebenfalls nur selten Rechtshilfe vor dem Reichskammergericht gesucht. Die 23 Appellations- und sechs erstinstanzlichen Verfahren verteilen sich relativ gleichmäßig auf die Jahre vor 1607 . Allerdings verwundert im

\footnotetext{
${ }^{123}$ A.D. Moselle, B 11084 und 11091.

${ }^{124}$ A.C. Verdun, BB 1.

${ }^{125}$ Ibid. BB 1.

${ }^{126}$ Zur Nutzung der Pariser Gerichte siehe oben, Kapitel III.8. Nach 1567 trafen nur noch vier Berufungen aus Verdun in Speyer ein: 1577 (A.D. Moselle, B 11092), 1582 (B 11082 und 10767) und 1600 (B 10855).

${ }^{127}$ A.D. Meuse $11 \mathrm{~F} 11,4-15$ und 16.
} 
Vergleich zu den übrigen Territorien, wie spät hier insbesondere die Berufungen einsetzen: Bis zum Jahr 1566, in dem in der Stadt Metz, in Verdun und weniger deutlich auch im Hochstift Metz die Verfahren bereits deutlich abgeebbt waren, wurden hier nur vier Berufungen vor dem Reichskammergericht eingelegt ${ }^{128}$. Die erstinstanzlichen Verfahren fallen ebenfalls nicht in die in Metz, Vic und Verdun beobachtete Hochphase der Jahre 1550-1565, sondern datieren deutlich früher und enden bereits um $1545^{129}$.

Ein beachtlicher Teil der Berufungen nach 1552 entfällt in Toul im Gegensatz zu Verdun auf die Zeit der herzoglich-lothringischen Herrschaft über die Stadt während der Amtszeit des Bischofs Charles de Lorraine-Vaudemont und der Religionskriege ${ }^{130}$. Nach 1595 wird noch einmal im Jahr 1597 eine Berufung eingereicht, dann finden sich zunächst keine Verfahren $m e{ }^{131}{ }^{131}$. Anders als in Verdun kam es aber in Toul auch nach 1600 noch zu einigen Verfahren: In den Jahren 1604 und 1607 wurden je zwei Berufungen gegen Urteile der chambre épiscopale, bzw. der dix justiciers vor dem Reichskammergericht eingelegt ${ }^{132}$. Während das Appellationsprivileg in Verdun eine deutliche Abschwächung der Berufungstätigkeit gebracht hatte, ist dies in Toul nicht zu beobachten: Bei einer insgesamt geringen Anzahl an Verfahren wurden nach der Erteilung im Jahr 1594 noch sechs Berufungen eingelegt. Hier könnte man einen Zusammenhang mit der Tätigkeit des königlichen président und der Leistung eines ersten Treueides auf den französischen König im Jahr 1607 vermuten. Wahrscheinlicher ist jedoch der Zusammenhang mit einer verstärkten Klagetätigkeit in Paris, zumal den Untertanen des Domkapitels dieser Weg seit 1612 auch ganz offiziell freistand, während der président von Metz sich noch lange Zeit sehr schwer tat, seine Zuständigkeit durchzusetzen ${ }^{133}$.

Betrachtet man den Gegenstand der Verfahren, bestätigen sich erneut die für die beiden anderen Städte und bischöflichen Territorien gemachten Beobachtungen. Darüber hinaus kam dem Reichskammergericht in Toul ähnlich wie in Verdun in den Jahren vor 1552 eine wichtige Funktion bei Kompetenzstreitigkeiten zwischen Stadt, Bischof und Domkapitel zu. So findet sich bereits 1533 eine Berufung der Stadtgemeinde Toul gegen ein Urteil zugunsten des dortigen Domkapitels, dem sich 1540 ein weiterer Proze $B$ anschlo $\beta^{134}$. Schon ein

\footnotetext{
${ }^{128}$ Noch dazu erfolgten diese Berufungen sehr früh, nämlich in den Jahren 1500 (A.D. Moselle, B 10778), 1522 (B 10727), 1533 (B 11079) und 1538 (B 10766).

${ }^{129}$ Hier ist nur eine Ausnahme zu nennen, ein Verfahren aus dem Jahr 1595 (ibid. B 11045).

${ }^{130}$ Neun von neunzehn Berufungen: Ibid. B 110949, 11060, 10728, 10768, 10962, 10837. $11010,10945,11042$.

${ }^{131}$ Ibid. B 10752.

${ }^{132}$ Ibid. B 1 1061, 10960, 10801, 11026.

${ }^{133} \mathrm{Vgl}$. oben Kapitel III.

${ }^{134}$ A.D. Moselle, B 11079 und 11080.
} 
Jahr darauf traf wiederum eine Klage in Speyer ein, diesmal vom Domkapitel gegen die Stadt. Kurz darauf wendete sich das Kapitel auch gegen die bischöflichen Amtsträger ${ }^{135}$. Die gleichen Parteien finden sich dann in den Jahren 1598,1618 , und 1619 vor dem königlichen Rat in Paris ${ }^{136}$. Gerade an diesem Beispiel wird deutlich, wie das Reichskammergericht von königlichen Institutionen in Paris abgelöst wurde.

\section{Resümee}

Die Reaktionen der Bevölkerung, aber auch der Magistrate und Bischöfe gegenüber der französischen Besetzung der Trois-Évêchés und dem zunehmenden Gebaren des Königs als Souverän ist teilweise auch mit dem Verhältnis dieser Städte und Territorien zum Reich zu erklären. Denn auch vor 1552 waren die Bindungen zum Reich eher locker und es sind in Metz, Toul und Verdun deutliche Bestrebungen erkennbar, sich der Reichssteuer und uber das Mittel der Appellationsprivilegien bis zu einem gewissen Maße auch der Reichsgerichtsbarkeit zu entziehen. Nach der Niederlage Karls V. vor Metz im Winter 1552 schien man im Reich die lothringischen Gebiete trotz vereinzelter Initiativen weitgehend verloren gegeben zu haben. Vor allem die Verhandlungen der Reichstage machen deutlich, daß die Reichsstände wegen der TroisÉvêchés nicht zu einem militärischen Konflikt mit Frankreich bereit waren.

An der gereizten Reaktion des Reichstages von 1570 auf das Metzer Gesuch, in Latein votieren zu dürfen, wird auch erneut die Bedeutung der Sprache deutlich. Bereits im Vertrag von Chambord hatten die protestantischen Fürsten dem König mit Metz, Toul und Verdun diejenigen Städte zugesprochen, die nit Teutscher sprach sein ${ }^{137}$. Auch bei Berufungen vor dem Reichskammergericht wird deutlich, daß der Sprachunterschied die Klagebereitschaft verringerte, denn die deutschsprachigen Vasallen des Bischofs von Metz legten wesentlich häufiger Berufung in Speyer ein als ihre französischsprachigen Landsleute.

Davon abgesehen scheint sich das Klageverhalten vor dem Reichskammergericht jedoch nur begrenzt als Gradmesser für die allgemeine Situation zu eignen. Dies ist zum einen darin begrundet, daß im Vergleich zu der großen Bedeutung, die dem Reichskammergericht von Seiten der königlichen Amts-

\footnotetext{
${ }^{135}$ Ibid. B 11076 und 11077.

${ }^{136}$ BnF, N.a.fr. 7099, fol. 163f., 263f.; Institut, Godefroy 356, fol. $2 f$.

137 Vertrag von Chambord, Geschichte in Quellen, hg. v. DICKMANN, Bd. 3, S. 197-199, hier 199.
} 
träger, aber auch in einigen Denkschriften aus der Bevölkerung zugemessen wurde, die tatsächliche Anzahl der Berufungen eher gering war. Zum anderen stehen beispielsweise die zahlreichen Klagen aus dem Hochstift Metz unter dem Bischof Henri de Bourbon, einem Sohn des französischen Königs Heinrichs IV., im Gegensatz zur proköniglichen Politik des Bischofs.

In der Stadt Metz hingegen, wo auch nach 1552 der noch immer weitgehend von den Patriziern kontrollierte Rat Berufungen vor dem Reichskammergericht entschieden ablehnte, haben ausgerechnet Mitglieder dieser Familien immer wieder Verfahren nach Speyer getragen. Insgesamt wurde der Großteil der Verfahren von Personen aus dem Adel, der städtischen Oberschicht und den Amtsträgern der Territorien angestrengt, wozu noch Körperschaften, vor allem Gemeinden, aber auch Klöster und Domkapitel kamen. Genau diese Gruppen aber begannen im 17. Jahrhundert vermehrt, ihre Verfahren vor dem conseil du roi entscheiden zu lassen. Besonders deutlich wird dies an den inneren Konflikten in Toul, wo die gleichen Parteien zunächst vor dem Reichskammergericht und später vor dem königlichen Rat zu finden sind. 
